\title{
Reflexões sobre a escrita da pesquisa como tecnologia de (re)criação de si
}

\section{Reflections about the writing of the research as technology of itself (re)creation}

Resumo: A escrita da pesquisa é foco das reflexões aqui apresentadas. A partir do registro de um acontecimento quando da coleta de informações para uma pesquisa de mestrado, problematiza-se a importância da narrativa de imprevistos que, uma vez alçados à condição de evento descrito, constituem-se como importantes dispositivos para a constituição do pesquisador. Nesse processo, a escrita da pesquisa é considerada como tecnologia: tecno, arte de enformação da realidade em matéria significante, que, no processo de enformação, (re)forma, (de)forma, (in)forma, enfim (re)cria a realidade e seu próprio autor. Isso é possível em razão da condição de mútua constituição entre sujeito que escreve e a escrita que se objetiva para a leitura de um outro que, por sua vez, (re)criará, a partir da sua posição axiológica, o próprio texto a ser lido.

Palavras-chave: Pesquisa. Escrita. Constituição do pesquisador. Metodologia.

Abstract: The writing of the research is focus of the reflections presented here. From the register of an event when of the collection of information for one master research of, it put in doubt the importance of the narrative of unexpected that, one time elevated to the condition of described event, constitute themselves as important devices for the constitution of the researcher. In this process, the writing of the research is considered as technology: tecno, art of forming of the reality in significant substance, that, in the process of forming, (re)form, (de)form, (in)form, at last (re)creates the reality and its own author. This is possible in reason of the condition of mutual constitution between the subject writer and the writing that objective itself for the reading of one another that, in turn, (re)will create, from its axiological position, the own text to be read.

Keywords: Research. Writing. Constitution of the researcher. Methodology.

ZANELLA, Andréa Vieira. Reflexões sobre a escrita da pes quisa como tecnologia de (re)criação de si. Informática na educação: teoria \& prática. Porto Alegre, v.11, n.1, p. 2837 , jan./jun. 2008

\author{
Andréa Vieira Zanella \\ Universidade Federal de Santa Catarina, Florianópolis, Brasil
}

\section{I ntrodução}

Desquisar é prática social complexa que busca (re)conhecer e/ou encontrar soluções para uma realidade igualmente complexa. Pressupõe relações entre pessoas em todo o seu processo, sendo várias as condições dialógicas que se apresentam:

a) pesquisador(a) e orientador(a), no caso de investigações ligadas a cursos de graduação ou programas de pós-graduação;

b) pesquisador(a) e pessoas que escolhe para participarem como sujeitos da pesquisa, o que caracteriza predominantemente as investigações no campo das ciências humanas e sociais;

c) pesquisador(a) e muitos outros - presentes e ausentes - com os quais se relaciona durante o percurso a ser trilhado.

Não é possível discutir, no escopo deste texto, as vicissitudes e efeitos dessas relações dialógicas, porém é fundamental reconhecer a impossibilidade de focar o objeto proposto para este artigo - a escrita da pesquisa, a ser afirmada como tecnologia de (re)criação de si - desconsiderando as condições de produção dessa própria escrita, as quais pressupõem inexoravelmente as relações apontadas em a, b e c. 
Essas relações são complexas e suas vicissitudes, considerando as condições históricas em que se vive e com a história que se quer (re)produzir, permitem afirmar que pesquisar é uma ação ética, estética e política. Ética, porquanto socialmente comprometida com alguma visão de mundo, com os valores, conhecimentos e crenças que (re)(de)formam o olhar do(a) pesquisador(a) e que se objetivarão na escrita do trabalho, escrita essa que difundirá, de modo explícito ou não, (im)possibilidade(s) para a existência humana.

Pesquisar é também uma prática estética, posto que se pauta em sensibilidades que estranham o instituído e reconhecem infinitas possibilidades de devir e acolhimento das diferenças que conotam ou podem vir a conotar a existência humana. É uma prática estética porque se funda em relações estéticas, ou seja, em relações sensíveis em que é possível reconhecer a potência criadora que afirma o ser humano enquanto humanidade ${ }^{1}$.

Por fim, pesquisar é uma prática política, na medida em que, como toda e qualquer ação humana, necessariamente se engaja em um projeto de vida, singular e coletivo, que se quer (re)produzir.

As dimensões ética, estética e política do pesquisar se objetivam no texto que apresenta o relatório do processo de produção de conhecimento e seus resultados. Nesse sentido, o relato da pesquisa é discurso que apresenta uma dimensão avaliativa, que objetiva um posicionamento de quem o escreve e demarca a posição axiológica de seu autor. Explicita-se com essa afirmação a minha própria posição axiológica em relação ao pesquisar, que entendo como processo não de explicitação de uma realidade dada, mas de sua própria reinvenção, posto que “[...] o processo de transmutação do mundo em matéria significante se dá sempre atravessado pela refração dos quadros axiológicos" (FARACO, 2003, p. 49).

Se pesquisar é reinventar a realidade, e não somente demonstrá-la ou explicá-la, a reflexão sobre o que se pesquisa, sobre os caminhos trilhados no percurso da investigação e o que resulta dessa prática social vinculase inexoravelmente com a reflexão sobre o processo de criação que caracteriza toda e qualquer pesquisa: criação de algum novo ob- jetivado na escrita que se divulga, e ao mesmo tempo (re)criação do(a) pesquisador(a), do(a) orientador(a) e dos muitos outros com os quais estes se relacionam, em encontros/ desencontros vários.

Para afirmar que pesquisar significa produzir algum "novo", é importante esclarecer que "novo" pode ser entendido tanto como a explicitação de algo que até então não tinha sido enunciado, portanto inédito ainda que fundado no já dito, quanto a apresentação de uma nova possibilidade de leitura para algo há muito tempo estudado/enunciado e cuja familiaridade nos cega para o que pode vir a ser (re)conhecido. Em qualquer das situações, o conhecimento e o intenso diálogo com o dito e o não dito é condição para o pesquisar, a base sobre a qual se assentarão as reflexões e as argumentações que podem vir a ser produzidas.

Sobre o processo de criação, Vygotski (1990), em obra onde discute a imaginação e arte na infância, esclarece que quem cria o faz a partir de um complexo processo em que aspectos da realidade são descolados dentre uma infinidade de possíveis, e combinados de múltiplas maneiras. As possibilidades de reconhecer como significativos alguns aspectos e não outros em determinado tempo e espaço, e descolá-los dentre uma infinidade de possíveis, afirma a condição singular e social de toda e qualquer pessoa: marcada pelas características do momento histórico em que vive, dialoga com essas características, trava (in)tenso diálogo marcado por movimentos de aceitação, oposição, recusa, acolhimento. Para usar uma terminologia do Círculo de Bakhtin, toda pessoa refrata, através de seu posicionamento axiológico, o que se lhe apresenta como realidade instituinte e, nesse movimento, (re)cria a própria realidade e a si mesmo.

A partir das contribuições de Vygotski e do Círculo de Bakhtin, e no diálogo com muitas outras, compreende-se portanto que o inusitado, o novo que se objetiva no processo de criação, é produzido com as infindáveis possibilidades de (de)composição, de recortes de fragmentos daqui e dali que são recompostos em novas combinações, em produções inovadoras, decorrentes tanto do que intencio-

\footnotetext{
${ }^{1}$ Sobre a concepção de estética aqui apresentada, ver Zanella (2006).
} 
nalmente se produz quanto dos acasos, dos improvisos, dos encontros inesperados que surpreendem com o que emerge. Improviso que é lugar do súbito, que dá vazão ao que irrompe sem qualquer restrição prévia e assim, desarmado, desconfigura o existente e o (re) cria.

Necessário, portanto, se faz pontuar que a própria ruptura, improvisação e criação emergem do diálogo com o que se apresenta como realidade instituinte: há, certamente, saberes variados, práticas sociais históricas e uma profusão de (in)verdades sob a base de toda atividade criadora. É no intenso diálogo com o que se apresenta como dado, na transgressão ao supostamente conhecido, que um novo discurso pode emergir e, com esse, novas possibilidades para se estar com outros e consigo mesmo, novas possibilidades dialógicas.

Esse processo não se dá pela certeza das linhas retas, mas fundamentalmente pela obliqüidade dos possíveis e a imprevisibilidade dos acontecimentos. No caso da pesquisa acadêmica, essa obliqüidade e imprevisibilidade também estão presentes, a se contrapor à previsibilidade pretendida com a compreensão de método restrita a passos a serem previamente delimitados e posteriormente seguidos. Os imprevistos são vários e se apresentam em todo o percurso da pesquisa, também marcando presença na redação do texto a ser apresentado a um outro: escrita fundada na palavra, signo essencialmente polissêmico, uma arena de conflitos, como dizem Voloshinov e Bakhtin (1976) que, na combinação com outros signos, possibilita não somente a expressão do que se quer dizer, mas fundamentalmente a sua (re)criação.

A escrita da pesquisa é, nesse sentido, considerada como tecnologia: tecno, arte de enformação da realidade em matéria significante, que, nesse processo de enformação, (re)forma, (de)forma, (in)forma, enfim (re)cria a realidade e seu próprio autor, posto a condição de mútua constituição entre sujeito que escreve e a escrita que se objetiva para a leitura de um outro que, por sua vez, (re)criará a partir da sua posição axiológica, o que se apresenta como texto a ser lido. Essa é a tese que nesse artigo objetivo defender.

\section{A escrita da pesquisa e algumas de suas vicissitudes}

Embora conceba a dupla dimensão da escrita como transformadora da realidade e de seu agente, é preciso reconhecer que a escrita apresentada como relatório final de pesquisa nem sempre é reveladora da angústia e das vicissitudes do processo de sua criação, bem como do intenso movimento de constituição de seu próprio autor. Assim como toda produção escrita, a escrita/relatório de pesquisa, que em outro momento me referi como escrita/descrita (ZANELLA, 2008), apresenta presumidos, ou seja, traz em suas linhas e entrelinhas o contexto extraverbal da enunciação, o horizonte espacial e ideacional compartilhado pelos falantes em interação, como definem Voloshinov e Bakhtin (1976). Na escrita/relatório de pesquisa, porém, em razão do gênero que a caracteriza, espera-se que os presumidos sejam traduzidos, ou que possam vir a ser reconhecidos, o que se apresenta como objetivo na tentativa de garantir a leitura que virá, ou que pelo menos que as intencionalidades do autor possam ser reconhecidas. Leitura prevista, captura do leitor projetada no desenho dos parágrafos e capítulos com suas seqüências deliberadamente previstas.

Mas como capturas são meramente projetos a provocar linhas de fuga, mesmo em se tratando de escrita descrita, acadêmica, pretensamente científica, esse projeto é intenção não garantida, pois por mais que as palavras sejam cuidadosamente escolhidas, os conceitos definidos, as reflexões alinhavadas com pretensa precisão ${ }^{2}$, todo texto que se apresenta a um outro é aberto a variadas interpretações, é aberto à emergência de palavras outras, às possibilidades de relações com textos e contextos vários.

Apesar de projeto fracassado, penso que a explicitação de alguns presumidos é fundamental na escrita da pesquisa, principalmente aqueles que permitem explicitar a complexidade que entretece o(a) pesquisador(a) e seu campo, a dialogia que conota as relações entre o sujeitos que pesquisam/são pesquisados. São vários os encontros/desencontros

\footnotetext{
2 Discussões mais aprofundadas sobre essas questões encontram-se em Zanella (2008)
} 
que conotam o processo de pesquisar como acontecimento a recriar seus protagonistas e que nem sempre estão visíveis na escrita/ relatório de pesquisa. Dar visibilidade a estes acontecimentos, por sua vez, é fundamental para que muitos outros possam compreender a condição inexoravelmente inventiva de toda e qualquer pesquisa.

Apresento como exemplo dos encontro/desencontros no processo de pesquisar uma situação (in)tensamente vivida e que exemplifica a complexidade das relações estabelecidas entre pesquisador(a) e as pessoas que participam do seu trabalho na condição de sujeitos da pesquisa, relações em que necessariamente o(a) orientador(a), uma vez implicado no próprio processo, se encontra entretecido. Ao mesmo tempo, essas situações possibilitam refletir sobre as vicissitudes do pesquisar e reiterar o anteriormente dito, ou seja, de que se trata de um processo tanto de criação de um novo texto quanto de (re)criação de si.

A situação que apresento foi vivenciada por uma orientanda de mestrado, aluna do Programa de Pós-Graduação em Psicologia da Universidade Federal de Santa Catarina (UFSC), e se caracterizou como potente dispositivo para o processo de constituição dessa aluna como pesquisadora e de mim mesma, posto que orientadora, parceira do processo de (re)criação e co-responsável pela sua formação. A situação foi vivida por Janaína Rocha Furtado no início da coleta de material para sua pesquisa, intitulada "Inventi(cidade): os processos de criação no graffiti" (2007).

Interessada em analisar os processos de criação no graffiti, Janaína estabeleceu contato com alguns grafiteiros de Florianópolis a quem havia sido apresentada anteriormente por um amigo comum. Quando da época da coleta de informações para a pesquisa foi procurá-los na loja de produtos Hip Hop que mantinham no centro da cidade, e já nesse primeiro encontro, conheceu outros jovens, que por sua vez os apresentaram a outros e assim pôde constituir sua rede de "informantes"3.
Mas o processo de coleta de informações não foi tranqüilo e de longe correspondeu às previsibilidades antecipadas no projeto de pesquisa apresentado para qualificação. Projetos são necessários, fundamentais diria, porém desde que assumidos como protocolos de intenções que orientam o pesquisar na medida em que, uma vez bem delineados, delimitam o olhar do(a) pesquisador em relação a um foco/ problema e às lentes teórico-metodológicas que nortearão as análises a serem realizadas. Nesse sentido, um projeto de pesquisa é indispensável. Mas há certa pretensão de previsibilidade nos projetos, a ilusão da garantia em relação aos encontros a serem cunhados e o que daí pode advir que necessariamente precisa ser. Afinal, pesquisar é imergir na densidade de acontecimentos e poder destes se afastar, em um movimento exotópico ${ }^{4}$, de distanciamento em relação ao vivido para, com o excedente de visão que esse distanciamento permite, poder escrever sobre o processo e dar-lhe acabamento, como diz Bakhtin (2003) ao referir-se à produção artística. E por que não pensar na escrita da pesquisa também como arte? Nesse caso, o acabamento da personagem, do relatório da pesquisa, alça seu criador/pesquisador à condição de artista, autor de uma escrita que se apresenta como abertura a muitas outras.

Voltemos à Janaína e sua pesquisa: vou me deter neste texto aos procedimentos para coleta de informações, igualmente importantes de serem previstos, mas ao mesmo tempo alçados à condição de possibilidades a serem revistas, afirmadas, abandonadas ou modificadas em razão das imprevisibilidades que caracterizam os encontros com um outro. No caso da pesquisa por ela realizada, esses encontros se deram com jovens que se encontravam para um rolê, como diziam, ou seja, para graffitar e, com sua arte, inscrever na cidade o signo de sua autoria.

As possibilidades previstas por Janaína em seu projeto de pesquisa para o encontro com os jovens tiveram que ser, em razão de um

\footnotetext{
${ }^{3}$ Utilizo aqui a expressão "informantes", emprestada das pesquisas antropológicas, porém as aspas indicam um desassossego. Tradicionalmente os manuais de metodologia científica, para referência às pessoas com as quais se pesquisa, utilizam a expressão "sujeitos", que considero igualmente desconfortável. Ambas as palavras carregam uma dimensão dicotômica que opõe sujeito e objeto, informante e pesquisador que colhe a informação. Não sei que outra palavra usar, mas o importante é demarcar que penso a pesquisa em ciências humanas tal como a concebe Bakhtin (2003), ou seja, como uma relação entre duas ou mais pessoas que falam, que se expressam e que se constituem na própria relação instituída com o pesquisar.

${ }^{4}$ Bakhtin define exotopia como o distanciamento em relação ao personagem. Para o autor, "A atividade estética começa propriamente quando retornamos a nós mesmos e ao nosso lugar fora da pessoa que sobre, quando enformamos e damos acabamento ao material da compenetração" (BAKHTIN, 2003, p. 25)
} 
acontecimento que ela relata e que aqui vou apresentar, revistas. Previa investigar processos de criação no graffiti e nos parecia impossível pensar em outra forma de fazê-lo que não acompanhar os graffiteiros em ação, fazer-se partícipe da clandestina intervenção urbana, ainda que não para se fazer um deles, mas para observar e registrar os movimentos dos jovens, de seus corpos, de seus traços. Estar com os artistas no processo de criação de suas obras, na emergência de seus traçados e compartilhar com eles as vicissitudes do processo, condição para que algo sobre esse pudesse vir a ser dito.

Mas dificuldades começaram a aparecer desde os primeiros contatos. As previsibilidades esperadas, assentes em teorias de grupo a afirmar a atividade coletiva inaugurada em acordos prévios - encontros com hora, dia, local e tarefa conjuntamente e previamente acordados - não faziam parte da realidade daqueles jovens. As teorias psicológicas de grupos revelavam-se, com aqueles jovens, insuficientes para explicar a volatilidades dos encontros, as imprevisibilidades dos acontecimentos, as incertezas que impossibilitavam o planejamento sistematizado e o controle das condições propícias. Mas como foi possível a coleta de informações? Um dos jovens que Janaína principiara a conhecer, provavelmente em razão do vínculo, atendeu sua necessidade e agendou um encontro no qual ela poderia enfim iniciar o seu trabalho de campo. Demanda da pesquisadora, previsibilidade forçada, o inesperado (in)capturável. Descobrir isso foi deveras penoso, e o relato de Janaína é aqui apresentado nos ajuda a entender os efeitos da escrita no processo de constituir-se pesquisadora:

Naquela noite de novembro eu cheguei ao local de encontro aonde Mosquito iria me buscar as $22 \mathrm{~h} 30 \mathrm{~min}$. Senti medo de ter combinado um encontro naquela hora com pessoas que eu não conhecia, num lugar o qual eu não saberia movimentar-me e para participar de uma atividade ilegal. Tudo pela minha pesquisa, que eu queria tanto começar, não importasse qual a situação e quais os riscos, afinal, eu buscava viver a pesquisa. Não que me ocorresse medo daqueles grafiteiros especificamente, mas de toda a situação em que me deparava e a que estava por vir, pois havíamos combinado o encontro para as 23 horas e depois nos dirigiríamos aos outros grafiteiros que estariam aguardando na casa de um deles. De lá sairíamos para o rolê que, segundo eles, iria até umas 4 horas da madrugada quando então, eu seguiria para a casa do Lyn e ficaria lá até de manhã ou pegaria um ônibus, destes que passam pela madrugada, denominados mesmo de Madrugadão, para o meu bairro. Tudo acontecendo sem que eu tivesse me planejado ou sistematizado o meu próprio lugar ou os meus próprios interesses daquele encontro. Tudo muito rápido sem esquemas que eu imaginava fazer uso e ter tempo de construir no início da coleta de dados, da entrada no campo. No fim, Mosquito não apareceu porque acabaram cancelando o rolê para aquela noite. Eu não tinha celular e não havia me precavido de levar os telefones deles para ligar caso ocorresse algum desencontro. Tinha apenas uma mochila com um spray, dez reais e um caderno que serviria para anotar as observações do acontecido. Depareime mais uma vez com minhas próprias armadilhas, eu imaginava que tudo se desenvolveria ao meu modo e não ao modo daquelas pessoas. Não havia me apercebido da possibilidade do encontro não ocorrer justamente porque ele estava posto pra mim como algo absolutamente necessário e importante, mas não para aquelas pessoas, que nem me conheciam e que não tinham para comigo o compromisso que eu pensara ter estabelecido em algumas poucas horas antes. Ao distanciar-me da situação apresentada, num excedente de visão que me permitia enxergar para além da minha própria perspectiva, pude compreender o acontecido no conjunto de relações mais amplas. O que aconteceu? Era meia noite, eu estava num lugar que eu não conhecia, no meio de uma avenida escura, onde não passavam ônibus para o centro de Florianópolis e eu não sabia o que fazer para chegar em casa. Eu mal havia avisado a pessoa com quem eu vivia para qualquer emergência (FURTADO, 2007, p. 48).

O trecho apresentado é extenso, mas penso que vale a pena refletir sobre várias questões que ali se apresentam. À primeira vista, e no primeiro parágrafo, chama a atenção o relato do medo, a descrição de uma condição de incerteza e insegurança diante de um - ou vários - desconhecidos. Eram desconhecidas as pessoas que, em um contato algumas horas antes, tinham sido por Janaína alçadas à condição de sujeitos da pesquisa. Era desconhecida aquela hora, aquele lugar, e a própria cidade: a Floripa que se revelava a J anaína era uma entre as várias cidades contemporâneas, "[...] lugares cheios de desconhecidos que convivem em estreita proximidade", como afirma Bauman (2005, p. 33). E diante do desconhecido, revela-se a angústia e o medo, condições que se originam na inevitável incerteza da própria existência humana, mas que são historicamente vinculados ao que se institui como diferente, como diferença.

Batista (2003) descreve como se modificam historicamente os focos do medo na 
cidade do Rio de Janeiro, até chegarmos à obsessão pela segurança pública e às políticas higienistas que justificam as práticas de extermínio na que já foi um dia a capital do país. Realidade que não se distancia da cidade reconhecida como a de melhor qualidade de vida, onde Janaína desenvolveu sua pesquisa, cidade que, apesar da alcunha, também provoca medo: afinal, o mito das classes perigosas (COIMBRA, 2001) e dos locais perigosos é cunhado diuturnamente para todas as pessoas plugadas nos noticiários televisivos. Medo que se alastra para todo tempo/espaço/ condição que se apresenta como outro, como estranho em relação aos territórios por onde se costumava transitar.

Esse medo Janaína registra e, ao fazê-lo, oportuniza que possamos, na condição de leitor, reconhecer nossos próprios medos e incertezas, e ao mesmo tempo fazer frente a eles. Mas continuemos dialogando com a sua narrativa. A afirmação de que o medo era "[...] de toda a situação em que me deparava e a que estava por vir...", pode ser analisada em relação a outra frase, apresentada logo a seguir:

Tudo acontecendo sem que eu tivesse me planejado ou sistematizado o meu próprio lugar ou os meus próprios interesses daquele encontro. Tudo muito rápido sem esquemas que eu imaginava fazer uso e ter tempo de construir no início da coleta de dados, da entrada no campo.

Que planejamento e sistematização poderiam dar conta de evitar o medo diante do desconhecido? Que esquemas poderia ter imaginado e postos em ação, a evitar a angústia que vivenciou? Que vozes sociais podem ser ouvidas nessa assunção de imprecaução? Será que um rigoroso planejamento de pesquisa teria evitado o acontecimento? E o que isso poderia significar?

Várias perguntas, muitas incertezas. O distanciamento possibilitado pela escrita do acontecimento, e o excedente de visão que Ihe permitiu apresentar a um outro, leitor, e a si mesma, a situação vivida para que pudesse ser analisada, são fundamentais para a compreensão do que aconteceu com ela e da própria escrita como tecnologia de (re)criação de si. Encontrava-se em um local desconhecido, com parcos recursos para fazer frente ao inusitado da situação, uma lata de spray na mochila a denunciar a intenção da clandestini- dade planejada como mote para o pretendido registro de imagens e palavras que constituiriam o corpus de sua pesquisa. Lata de spray, arma da luta de muitos jovens contra a invisibilidade a que são relegados, naquela condição destituída de seu poder frente à batalha imaginária que estava a travar contra o medo da cidade.

Afirma Bauman (2005, p. 31) que

As cidades contemporâneas são os campos de batalha sobre os quais convergem, por um lado, os poderes mundiais e, por outro, as razões de ser obstinadas de cada um dos seus habitantes, que se entrechocam e combatem em busca de um acordo satisfatório ou minimamente tolerável: um tipo de convivência que se espera poder constituir uma paz duradoura, mas que, regra geral, não consegue ser mais do que um armistício, uma trégua que permite a reparação das defesas que abrem brechas e a reorganização das tropas em vista do próximo confronto. É este confronto, com efeito, e não um fator isolado independente, que move e orienta a dinâmica da cidade na época da modernidade líquida.

Seria a situação vivida um confronto postergado? Que batalhas outras enfrentaria Janaína durante sua pesquisa? Que medos outros - e seus muitos efeitos - teria que encarar? Janaína conseguiu voltar para casa, com os poucos reais que tinha, e no dia seguinte foi até a universidade para conversarmos. Nesse momento trago os meus próprios medos, igualmente entretecidos naqueles acontecimentos, e de certa forma importantes para a reflexão sobre o processo de constituição do(a) pesquisador(a) e de minha condição de orientadora.

Fiquei tão desalojada quanto ela, estarrecida não com o imprevisto e o desencontro, característicos de todo e qualquer processo de pesquisa aberto a novas possibilidades de se produzir conhecimentos, mas diante da possibilidade do que poderia ter acontecido. Com tantos relatos escabrosos a povoar os jornais diários, com a presença onisciente dos discursos de aumento da criminalidade, esse demônio contemporâneo (BATISTA, 2003), fui também assaltada pelo medo.

Foi preciso um tempo para empreendermos juntas o movimento exotópico, o distanciamento necessário à compreensão do acontecimento e seus efeitos. Conversamos inicialmente sobre o que aconteceu, sobre possíveis equívocos no delineamento da pesquisa, sobre possíveis sentidos para o não acontecimento 
do primeiro rolê que Janaína iria registrar e que se transformou em esse outro acontecimento. Das reflexões assentes nas escolhas, passamos à problematização dos efeitos do vivido em nós: o que foi que nos desalojou e desassossegou? Que desencontro foi esse? Que previsibilidades presumidas apresentavam-se nesse primeiro momento de coleta de informações? O que a imprevisibilidade e o próprio acontecimento permitiram à pesquisadora e a mim mesma, na condição de orientadora, problematizar?

No caso da pesquisa de Janaína, o deslocamento que a experiência nos provocou foi o mote para o distanciamento e a reflexão que cunhamos sobre o vivido e possibilidades outras para a investigação, necessariamente reinventada. Outros caminhos precisaram ser trilhados, as entrevistas voltaram à pauta como condição para os encontros, para o estar junto aos jovens no processo de graffitar. Entrevistas/conversas, acontecimentos que irromperam em situações não convencionais, em contextos e tempos variados, no ritmo dos improvisos e necessidades que foram, a partir dos encontros primeiros, sendo partilhadas com os próprios jovens.

Da fala para um outro - desconhecido paulatinamente foram solicitadas pelos sujeitos que, nas trocas e conversas, reivindicavam aqueles momentos e reconheciam, no registro e análise de suas produções artísticas, possibilidades outras para o reconhecimento da autoria. Pesquisa como (co) produção, implicação na tessitura que se objetivou em leituras e reflexões conjuntas sobre as análises na medida em que iam sendo tecidas, bem como no texto final que apresenta seus nomes, suas obras, seus discursos. Pesquisa que foi produzida não no encontro de um pesquisador que pergunta e sujeitos que respondem, mas no intenso diálogo em que as palavras de um se fundam nas palavras do outro e, uma vez proferidas, apresentam-se como abertura a novas palavras.

Mas além das mudanças no desenvolvimento da pesquisa, fundamentais para a sua consecução, o acontecimento aqui apresentado permitiu trazer à tona algo que foi possível reconhecer como fundamental nesse processo de (re)criação do próprio pesquisar: a escrita da pesquisa. O dito e o silenciado. O que se pode ouvir, e os muitos ciscos que são produzidos no percurso e que costumeiramente são varridos para as lixeiras do esquecimento.

Trazer para o corpo do texto que se apresenta como relatório da pesquisa as vicissitudes do processo, alguns dos seus muitos ciscos, os tropeços, os imprevistos e seus efeitos para o sujeito que pesquisa, revelou-se como fundamental para o movimento de (re)criação da pesquisa e do próprio pesquisador. Narrativa que engendra a reflexão sobre o vivido, que permite ter como foco de análise não somente o discurso do outro, mas o próprio discurso que com este se origina e a muitos outros de destina. Pesquisador(a) e pessoas com as quais pesquisa, todos sujeitos do discurso e sujeitados às turbulências que nos assaltam tal como os desconhecidos que evitamos.

Conceber à escrita esse status assenta-se no reconhecimento de que se (re)cria com a palavra tanto o interlocutor que se apresenta como parceiro do diálogo que possibilitou sua emergência - a realidade pesquisada, com seus variados protagonistas - quanto o seu próprio autor. I sso porque “[...] escrever não é certamente impor uma forma [de expressão] a uma matéria vivida" (DELEUZE, 1997, p. 11). Ao contrário, escrever é (re)criar o vivido e, com o distanciamento possibilitado pela leitura do que se objetivou em palavras, ressignificá-lo, sempre e sempre. A escrita é assim entendida como tecnologia, como importante ferramenta que permite inscrever em um tempo e para um tempo outro um acontecimento que, uma vez objetivado em um discurso, está aberto a infinitas possibilidades de novos discursos e novos tempos.

Por sua vez, quem escreve, inscreve a si mesmo em um tempo outro, e com esse processo abre possibilidades para si de alçar condições outras de ser e estar no mundo. Foucault (1992) destaca, seja na escrita dos hypomnemata, seja nas correspondências, a dimensão da escrita como elemento do treino de si, como constitutiva de si. Sendo a escrita criação, é possível compreender essa dupla dimensão da escrita como (re)criação da realidade e (re)criação de si, pois os processos de criação são constitutivos das pessoas em relação na medida em que dão fluxo ao movimento de vir a ser e a abertura a novas condições cognitivas, afetivas, volitivas, de relações consigo mesmo e com outros.

Escrita nesse sentido é, como já afirmado anteriormente, tecnologia, arte que (re)cria tanto a realidade que se apresenta a um ou- 
tro, bem como seu próprio autor, posto que a escrita não é mera transposição para o papel de um pensamento prévio: ao escrever, os pensamentos se (trans)formam e, no processo de sua produção, transforma-se o próprio escritor, seus pensamentos, suas emoções e sua condição axiológica. A escrita da pesquisa e tantas outras artes da existência e técnicas de si, configuram-se como:

[...] práticas reflexivas e voluntárias através das quais os homens não somente se fixam regras de conduta, como também procuram se transformar, modificar-se em seu ser singular e fazer com que sua obra seja portadora de certos valores estéticos e responda a certos critérios de estilo (TUCHERMAN, 2005, p. 45).

Por sua vez, a escrita objetivada possibilita também a (re)criação do leitor que dialoga com o texto, posto que às palavras proferidas este apresenta contrapalavras, que podem vir a se objetivar ou não em um outro texto a engendrar leituras outras e mover a dialogia característica do viver.

Escrita de pesquisa, desse modo, é muito mais que relato: é tecnologia de si, narrativa da relação de quem escreve/pesquisa com a realidade investigada, sob o prisma de seu autor. Processo objetivado que se apresenta como condição para o distanciamento em que a pessoa que escreve se alça à condição de outra de si mesma. Movimento de alteridade mediado pela palavra que ganha corpo ao ser proferida, e que na medida em que é cunhada, transforma o seu próprio criador.

\section{Das redes tecidas e algumas de suas implicações: alguns comentários mais sobre a escrita/ relatório de pesquisa}

Para dar um fechamento a esta escrita, volto ao relato de Janaína, exatamente naquele momento em que arbitrariamente fechei aspas para tecer as reflexões que apresentei:

Tudo deu certo, senão eu não estaria escrevendo esse texto neste instante. No entanto, estes primeiros momentos foram muito importantes para que eu me refizesse enquanto pesquisadora, reconstituísse meu lugar ali entre estas singularidades, e delineasse um outro tempo para que a relação se estabelecesse. Um tempo que não era o meu, mas o da relação mesmo, o tempo do entre em que se leva para estabele- cer um contato e, mais do que isso, estabelecer um encontro realmente significativo para ambas as partes, pesquisadora e grafiteiros. A pesquisa deveria se mostrar tão importante para eles quanto era para mim e era com isso que eu deveria me preocupar a partir de então (FURTADO, 2007, p. 48-49).

Essa continuidade da narrativa é tão importante como seu começo, e eu poderia tê-la apresentado como um todo, mas a pausa para entretecer com as palavras dela as minhas contrapalavras é o leitmotiv deste texto. Pausa a explicitar alguns presumidos, fundamentalmente a angústia que o acontecimento nos provocou, o medo que dali emergiu e o modo como mobilizou-nos a repensar a ida a campo e a escrita da pesquisa.

O medo e a insegurança diante do desconhecido, da imprevisibilidade de acontecimentos que fugiram às delimitações antecipadas como caminho a ser percorrido no projeto de pesquisa, foram fundantes do movimento de (re) invenção de trajetórias e estratégias, bem como de nossos lugares de pesquisadora e orientadora. Provocaram um movimento que lembra a frase do escritor português J osé Saramago, no filme/documentário "Janelas da alma" (2002): “[...] para conhecer algo é necessário dar-Ihes a volta". Procuramos então, dar a volta, olhar o acontecido sob diferentes ângulos, não em busca de uma suposta verdade, de sentidos unívocos; ao contrário, procuramos sentidos vários, possibilidades próximas e remotas que nos ajudassem a entender as escolhas feitas e suas implicações, a imprevisibilidade e o medo que em nós provocou. A frase de Saramago nos convida a esse movimento, a darmos a volta, que nos exercitemos no sentido de sairmos de um mesmo lugar. Convida à procura de outros ângulos, outros aspectos, outros sentidos, enfim, possibilidades outras a serem reinventadas para os encontros que se apresentam no processo de pesquisar. Esses encontros, por sua vez, podem levar a direções imprevistas no que se refere à constituição das pessoas em relação.

Pesquisar, nesta perspectiva, significa correr riscos, estar com desconhecidos e enfrentar os muitos medos que esse (des) encontro produz ou faz emergir. Medo da cidade, do outro, do inesperado: reconhecê-lo e problematizá-lo é fundamental para que a insegurança em relação ao desconhecido não transforme o 
pesquisar em uma entediante explicitação de algo previamente sabido, e que seja possível viver a pesquisa como uma aventura, factível ao pesquisador que se permite surpreender pelas imprevisibilidades dos (des) encontros. A escrita da pesquisa, nessa perspectiva, é tecnologia para o enfrentamento dos medos, para a aproximação em relação ao desconhecido, à diferença, que transforma os corpos e suas possibilidades de afecção.

Corpos nossos transformados, (in)vestidos com as incertezas do devir; sensibilidades reinventadas com as intensidades dos acontecimentos e a necessária reflexão que estes provocaram. Janaína relata que:
Foi sem saber como estar entre grafiteiros que estive e sem saber como iniciar que iniciei. Pus meu corpo-pesquisadora em movimento na direção destes corpos-grafiteiros alheios, buscando por meio de minha sensibilidade compreender as suas dinâmicas próprias no contorno da cidade e acabei por constituir a minha própria dinâmica singular de pesquisar (FURTADO, 2007, p. 46).

Foi vivendo com Janaína, assim como com outros orientandos e orientandas, as vicissitudes características do pesquisar como prática social ética, estética e política que, na condição de pesquisadora/orientadora, reinvento o meu próprio corpo e o meu lugar nessa intrincada teia em que nos entretecemos.

\section{Referências}

VOLOSHINOV, Valentin; BAKHTIN, Mikhail. Discurso na vida e discurso na arte: sobre a poética sociológica. Tradução para fins didáticos de: Carlos Alberto Faraco e Cristóvão Tezza. Mimeografado. Tradução de: Lê discours dans le vie et le discours dans la poésie. Contribución à une poétique sociologique. In: VOLOSHINOV, Valentin. Freudism. New York: Academic Press, 1976.

BAKHTIN, Mikhail. Estética da criação verbal. 4. ed. São Paulo: Martins Fontes, 2003.

BATISTA, Vera Malaguti. O medo na cidade do Rio de Janeiro: dois tempos de uma história. Rio de Janeiro: Revan, 2003.

BAUMAN, Zygmunt. Confiança e medo na cidade. Lisboa: Antropos, 2005.

COIMBRA, Cecília. Operação Rio: o mito das classes perigosas - um estudo sobre a violência urbana, a mídia impressa e os discursos de segurança pública. Niterói: Intertexto, 2001.

DELEUZE, Gilles. Crítica e clínica. Tradução de Peter Pál Pelbart. São Paulo: Ed. 34, 1997.

FARACO, Carlos Alberto. Linguagem \& Diálogo: as idéias lingüísticas do Círculo de Bakhtin. Curitiba: Criar Edições, 2003.

FOUCAULT, Michel. O que é um autor? Lisboa: Passagens, 1992.

FURTADO, Janaina Rocha. Inventi(cidade): os processos de criação no graffiti. Florianópolis, 2007. 165 f. Dissertação (Mestrado em Psicologia) - Centro de Filosofia e Ciências Humanas, Universidade Federal de Santa Catarina, Florianópolis, 2007. Disponível em: <http://www.cfh.ufsc.br/ ppgp>. Acesso em: 2007.

JANELAS da alma. Apresentação: José Zaramago et al. Produção: Flávio Tambellini. Direção: João Jardim e Walter Carvalho. [S.I.: s.n.], 2002. 1 videocassete (73 min), VHS, son., color.

TUCHERMAN, Ieda. Michel Foucault hoje, ou ainda: do dispositivo de vigilância ao dispositivo de exposição da intimidade. Revista FAMECOS, Porto Alegre, n. 27, p. 40-48, agosto de 2005.

VYGOTSKI, Lev Semionovich. La imaginacion y el arte en la infancia. Madrid: AKAL, 1990. 
ZANELLA, Andréa Vieira. "Pode até ser flor se flor parece a quem o diga": reflexões sobre educação estética e o processo de constituição do sujeito. In: ROS, Sílvia Zanatta da; ZANELLA, Andréa Vieira; MAHEIRIE, Kátia (Orgs.). Relações estéticas, atividade criadora e imaginação: sujeitos e/em experiência. Florianópolis: Ed. UFSC, 2006. p. 33-47.

ZANELLA, Andréa Vieira. Escrita e criação. In: AGUIAR, Fernando; GUIMARÃES, Beatriz (Orgs.). Interfaces em psicanálise e escrita. São Paulo: Casa do Psicólogo, 2008. p. 63-72.

Recebido em maio de 2008

Aceito para publicação em junho de 2008 